\title{
Standardized Fraction of Turbinaria ornata Alleviates Dextran Sulfate Sodium-Induced Chronic Colitis in C57BL/6 Mice via Upregulation of FOXP3 ${ }^{+}$ Regulatory T Cells
}

\author{
Na-Hyun Kim ${ }^{1}$, Seon Min Lee ${ }^{1}$, Yun Na Kim ${ }^{2}$, You-Jin Jeon ${ }^{3}$, Jeong-Doo Heo ${ }^{1}$, \\ Eun Ju Jeong $2, *$ (D) and Jung-Rae Rho ${ }^{4, *(D)}$ \\ 1 Gyeongnam Department of Environment \& Toxicology, Korea Institute of Toxicology, 17 Jegok-gil, \\ Munsan-eup 52834, Korea; nhkim@kitox.re.kr (N.-H.K.); smlee84@kitox.re.kr (S.M.L.); \\ jdher@kitox.re.kr (J.-D.H.) \\ 2 Department of Agronomy and Medicinal Plant Resources, Gyeongnam National University of Science and \\ Technology, Jinju 52725, Korea; skdbssk@naver.com \\ 3 Department of Marine Life Sciences, Jeju National University, Jeju 63243, Korea; youjin2014@gmail.com \\ 4 Department of Oceanography, Kunsan National University, Kunsan 54150, Korea \\ * Correspondence: ejjeong@gntech.ac.kr (E.J.J.); jrrho@kunsan.ac.kr (J.-R.R.); Tel.: +82-55-751-3224 (E.J.J.); \\ +82-463-69-4606 (J.-R.R.)
}

Received: 18 August 2020; Accepted: 15 October 2020; Published: 20 October 2020

\begin{abstract}
Turbinaria ornata is a tropical brown algae (seaweed) known to have anti-inflammatory properties. In this study, we analyzed T. ornata extract (TOE) using liquid chromatography quadrupole time of flight mass spectrometry (LC-QTOF-MS) and nuclear magnetic resonance (NMR) and evaluated the in vivo efficacy of TOE against dextran sulfate sodium-induced chronic colitis in C57BL/6 mice. The bioactive fraction of TOE was administered orally daily for 6 weeks to mice under different treatments normal, colitis, and colitis + conventional drug (5-aminosalicylic acid, 5-ASA). Regarding clinical manifestation, the disease activity index and colon length of the colitis + TOE group were significantly reduced compared to those of the colitis group. The results of myeloperoxidase activity and histopathological examination showed similar results. Western blot analysis of colon tissues revealed that cyclooxygenase-2, tumor necrosis factor alpha (TNF- $\alpha$ ), and phosphorylated signal transducer and activator of transcription-3 (p-STAT3) were significantly decreased in the colitis + 5-ASA group, whereas forkhead box P3 (FOXP3) was increased. qPCR results showed changes in T cell subsets; the administration of TOE upregulated regulatory T cell (Treg) expression, although T helper 17 cell (Th17) expression did not change significantly. Interestingly, the colitis + TOE group showed high levels of both Th1 and Th2 transcription factors, but the secreted cytokine interferon (IFN)- $\gamma$ and interleukin (IL)-4 remained unchanged and somewhat reduced. Additionally, TNF- $\alpha$ gene expression was significantly reduced in the colitis + TOE group. IL- 6 mRNA levels were also decreased, although not significantly. Four compounds were structurally elucidated using 1Dand 2D-NMR spectroscopy, and five compounds were fully identified or tentatively characterized using LC-QTOF-MS. In conclusion, TOE could alleviate chronic colitis via upregulation of Foxp $3^{+}$Treg cells and production of the anti-inflammatory cytokine IL-10, which directly inhibits macrophages and pro-inflammatory cytokine synthesis, leading to reduced colitis.
\end{abstract}

Keywords: Turbinaria ornata; brown algae; ulcerative colitis; dextran sulfate sodium-induced chronic colitis; regulatory T cell; interleukin-10; tumor necrosis factor- $\alpha$; phosphorylated signal transducer and activator of transcription-3 


\section{Introduction}

Ulcerative colitis (UC) is a type of inflammatory bowel disease (IBD), which is an idiopathic, chronic obstructive disease with typical recurrent episodes of colitis symptoms [1,2]. Recently, it has been acknowledged that UC mainly affects young adults (15 to 25 years old) in western countries, and its prevalence has increased over the years with no effective cure [3,4]. Although the pathogenesis of UC is not yet fully understood, many factors have been suggested as possible causes of UC, such as genetic abnormalities, environmental stresses, gut microbiota, and immune disorders [5].

IBD is known to initiate when the intestinal epithelial barrier is broken down by toxic chemicals, pathogens, or idiopathic causes [6]. Once this barrier collapses, the underlying tissues are exposed and attacked by gut microbiota, leading to the recruitment of leukocytes into the lamina propria and causing uncontrolled inflammation [6]. During the progression of UC, activated macrophages produce pro-inflammatory cytokines such as tumor necrosis factor alpha (TNF- $\alpha$ ), interleukin (IL)-1 $\beta$, IL-6, and IL-12 which attract neutrophils to the colonic mucosa, and directly contribute to crypt abscess and ulcerative lesions by producing reactive oxygen species and proteolytic enzymes $[7,8]$. Particularly, TNF- $\alpha$ is a major pathological cytokine that can affect the activation and progression of colitis by including direct disruption of the intestinal epithelial barrier integrity, provocation of epithelial cell death, and co-stimulation of effector T cells toward further chronic inflammation $[9,10]$.

It was also revealed that IBD has been associated with exaggerated cluster of differentiation $4(\mathrm{CD} 4)^{+} \mathrm{T}$ cell response [11]. In the normal healthy state, $\mathrm{CD}^{+} \mathrm{T}$ cell subsets exist in homeostasis so that they can resolve pathogens and inflammation [12]. However, under IBD conditions, these normal processes are disrupted [12]. The Th1 subset, differentiated by IL-12 stimulation, expression of transcription factor T-bet, and release of interferon (IFN)- $\gamma$, IL-6, and IL-12 is predominant in Crohn's disease (CD), whereas Th2, influenced by IL-4 or IL-5, is dependent on GATA binding protein 3 (GATA3) and its secreted cytokines IL-4, IL-5, and IL-13 are activated in UC. In addition, both CD and UC are commonly exhibited in Th17 subsets that are differentiated by the transcription factor retinoic acid-related orphan receptor $\gamma \mathrm{t}(\mathrm{ROR} \gamma \mathrm{t}$ ) and produce IL-17, IL-21, and IL-22, whereas the forkhead box P3 (FOXP3)-induced regulatory T cell (Treg) subset is decreased [13-15]. Many controversies remain over how these immune imbalances work on UC [16]; however, the investigation of these immune responses is important to lead toward a new UC drug discovery.

Regarding signal pathways, signal transducer and activator of transcription-3 (STAT3) is known to play a central role in IBD. It is widely expressed in various cell types, such as T cells, macrophages, and epithelial cells, and is activated mainly by IL-6 and leads to chronic inflammation [17]. In a recent study, STAT3 was activated in many patients with IBD and increased STAT3 was directly correlated with the severity of colitis and contributed substantially to colitis $[17,18]$.

Conventional drugs that are clinically applied to patients with UC include anti-inflammatory agents such as corticosteroids and 5-aminosalicylic acid (5-ASA), immunosuppressants (e.g., azathioprine), and biological agents (e.g., infliximab) [19]. The 5-ASA is used as a first-line treatment for patients with mild and moderate UC owing to fewer side effects than those with other drugs. However, most of these are not adequate for long-term administration and/or cause significant side effects [20]. In these circumstances, a search for improved therapeutic agents is essential [21]. Naturally derived compounds have long been used in treating human diseases. The superiority of natural products as drugs is derived from their structural diversity and complexity. Owing to the chemical complexity of natural products, they often tend to affect one or more targets, thus allowing more pathways to be influenced [22].

Turbinaria ornata is a tropical brown alga native to the South Pacific. To date, secondary metabolites, including cytotoxic secosqualene carboxylic acid and turbinaric acid, and phenolics with antioxidant and antibacterial activity have been reported from T. ornata [23-26] Recently, the anti-inflammatory activity of $T$. ornata containing fucoidan as the active constituent has been reported [27]. As a part of further studies to determine the anti-inflammatory potential of $T$. ornata, our research group newly identified bioactive metabolites, sulfoquinovosyl monoacylglycerols, which regulate intestinal inflammation 
in vitro [28]. It was found that the butanolic fraction of T. ornata extract and sulfoquinovosyl monoacylglycerols markedly downregulated inflammatory mediators in response to inhibition of nuclear factor kappa-light-chain-enhancer of activated B cells (NF- $\mathrm{kB}$ ) translocation to the nucleus in the Caco-2 and THP-1 co-culture system. Based on the results of the in vitro study, we attempted to evaluate the anti-inflammatory potential of the fraction of T. ornata extract in vivo.

For in vivo studies of UC, we used dextran sulfate sodium (DSS) which is widely used as a colitis inducer [29]. It is well known that colitis induced by DSS in murine models exhibits pathological features similar to those of human patients with UC - ulceration of the mucosal layer, bloody stool, and persistence of inflammatory cell infiltration in the distal colon [30]. In practice, treatment of three to five repeated cycles of low concentrations of DSS in mice is regarded as an effective and reproducible experimental method for chronic relapsing colitis [31]. Thus, a UC-like chronic relapsing colitis mouse model was induced with DSS, and the effects of the active fraction of T. ornata extract (TOE) were examined.

The therapeutic effects of TOE administration were compared to those of the conventional anti-inflammatory drug 5-ASA, and the underlying anti-inflammatory mechanisms associated with $\mathrm{CD}^{+} \mathrm{T}$ cell subsets were explored. Specifically, the disease activity index (DAI), colon length, and histopathology were used to evaluate clinical manifestations. Myeloperoxidase (MPO), cyclooxygenase-2 (COX-2), and TNF- $\alpha$ were selected for evaluating the overall inflammatory response. $\mathrm{CD}^{+} \mathrm{T}$ cell subsets in the colitis tissues were identified using qPCR-T-bet and Ifn- $\gamma$ for Th1, Gata-3 and Il-4 for Th2, Ror $\gamma t$ and Il-17 for Th17, and Foxp3 and Il-10 for Treg subsets. Tnf- $\alpha$ and Il-6 mRNA expression levels were also examined to assess macrophage and monocyte activity. Phosphorylated STAT3 (p-STAT3) was also examined by western blotting. In addition, the main constituents present in TOE that could be responsible for its pharmacological effects were identified using liquid chromatography quadrupole time of flight mass spectrometry (LC-QTOF-MS) analysis.

\section{Results}

\subsection{Isolation and Structure Elucidation of Compounds 1, 5-7 from TOE}

T. ornata was extracted with $90 \%$ aq. EtOH and fractioned using Sephadex LH20 into four fractions (M1-M4). Each fraction was evaluated for inhibitory activity against pro-inflammatory cytokines in vitro (Supplementary Materials S1). The M2 fraction, which exhibited good activity, was selected for further in vivo tests. The ${ }^{1} \mathrm{H}$ nuclear magnetic resonance (NMR) spectrum of M2 is shown in Figure 1, which contains severely overlapped signals in the upfield and oxygen-bearing regions. The separation of the main components from the M2 fraction was performed by high-performance liquid chromatography. The isolated compounds (1-9) were found to be steroids and sulfoquinovosyl monoacylglycerols (Figure 2). Using the combination of NMR and high resolution electrospray ionisation mass spectrometry (HRESIMS), and comparing with reported data, 1 was identified as 22E-3 $\beta$-cholesta-5,22-dien-24-one [32]. The structure of 5 was determined to be 1-O-[(7E)-9-hydroxyoctadeca-7-enoyl]-3-O-(6-sulfo- $\alpha$-D-quinovopyranosyl)-sn-glycerol, 6 as 1-palmitoyl-3-O-(6-sulfo- $\alpha$-D-quinovopyranosyl)-sn-glycerol, and 7 as 1-stearoyl-3-O-(6-sulfo$\alpha$-D-quinovopyranosyl)-sn-glycerol [28,33,34]. 


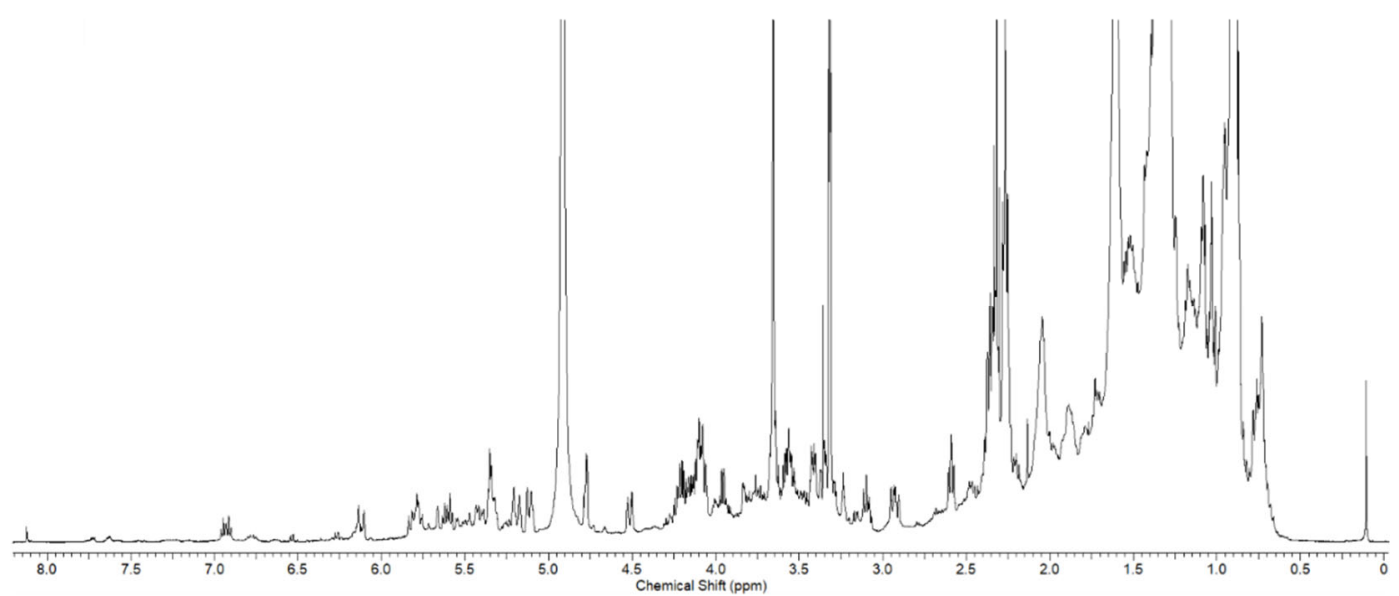

Figure 1. ${ }^{1} \mathrm{H}$ NMR spectrum of the M2 fraction of Turbinaria ornata extract (TOE) in $\mathrm{CD}_{3} \mathrm{OD}(500 \mathrm{MHz}$ for $\left.{ }^{1} \mathrm{H}\right)$.<smiles>C/C=C(\CC[C@H](C)[C@H]1CCC2C3C[C@H](O)C4=CC(=O)CC[C@]4(C)[C@H]3CC[C@]21C)C(C)C</smiles><smiles>C=CC(CC[C@H](C)[C@H]1CCC2C3CCC4=CC(=O)CC[C@]4(C)[C@H]3CC[C@]21C)(OO)C(C)C</smiles><smiles>O=S(=O)(O)CC1C(O)C(O)C(O)C1O</smiles>

5<smiles>[Y][Z](C)(=O)CCCCCC/C=C/[C@@H](O)CCCCCCCCC</smiles>

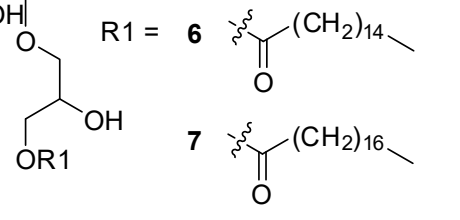<smiles>CCCCCCCCC[C@H](O)/C=C/CCCCCC(=O)O</smiles>

Figure 2. Structures of compounds 1-9 identified by NMR and LC-MS analysis from the M2 fraction of Turbinaria ornata extract (TOE).

\subsection{LC-QTOF-MS Analysis of T. ornata}

Based on the information on compounds isolated from TOE, LC-MS analysis was performed. LC-MS analysis enabled accurate identification of nine compounds, including those reported from Turbinaria sp., based on the MS and MS/MS fragmentation data. In the total ion chromatogram of the positive ion mode, cholesta-4,6-dien-3-one (2), and two steroids (3 and 4) reported from Turbinaria conoides were accurately identified from the MS and MS/MS spectra [35]. In the negative ESI chromatogram, three sulfoquinovosyl monoacylglycerols were observed with two main components. The first one was characterized as a sulfoquinovosyl monoacylglycerol with 9-hydroxyoctadec-7-enoic acid (8) based on accurate MS and MS/MS fragmentation data at $m / z 155$ and 171. Similarly, the other was identified as palmitic acid (9) (Figure 3). The retention time and characteristic fragment ions of all identified components (1-9) are presented in Table 1. 

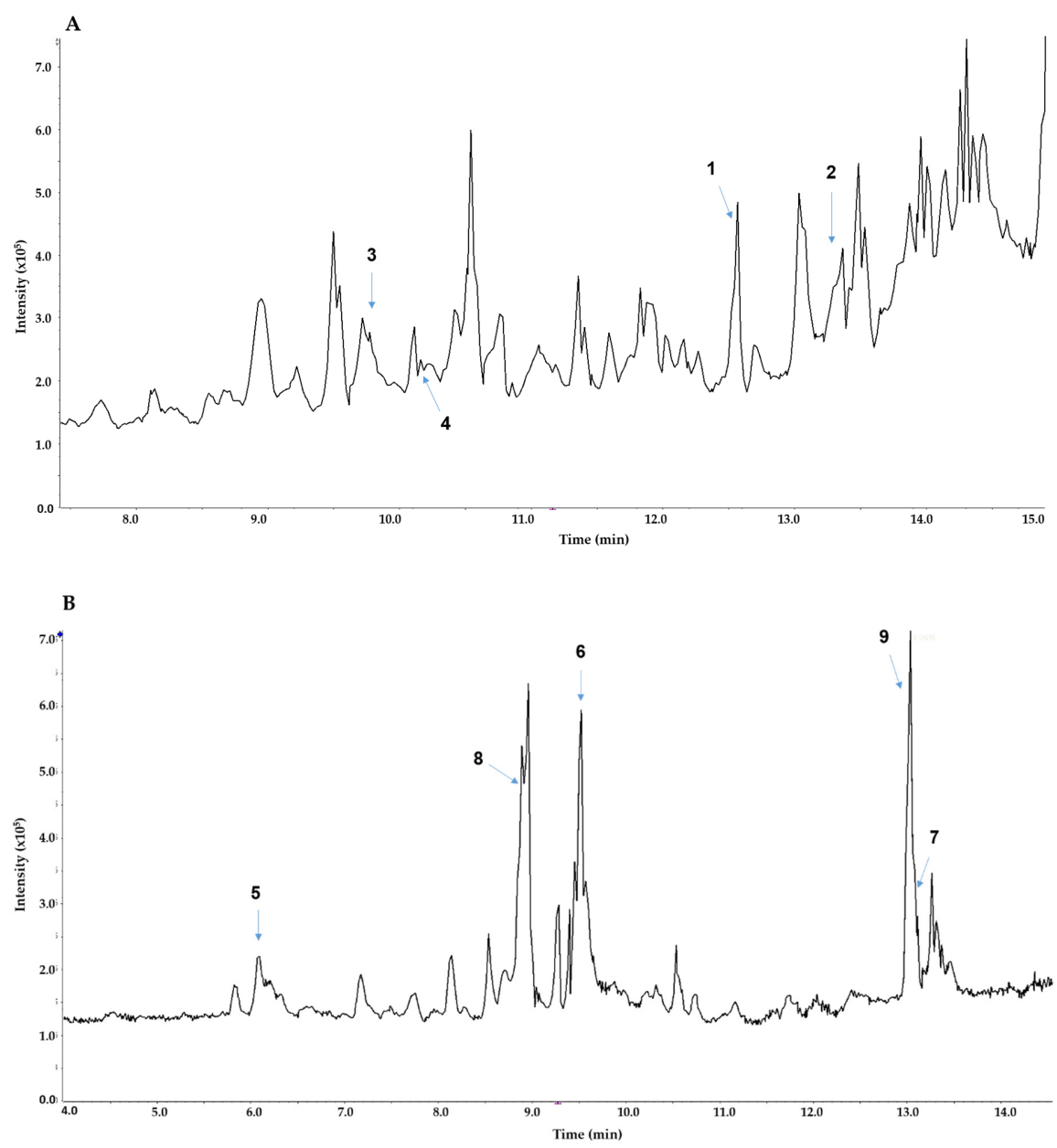

Figure 3. Total ion chromatogram and key peak identification of the M2 fraction of Turbinaria ornata extract (TOE) in positive mode (A) and negative mode (B).

Table 1. Identification of compounds in M2 fraction of Turbinaria ornata extract (TOE) using LC-QTOF-MS analysis.

\begin{tabular}{|c|c|c|c|c|c|}
\hline No & $\mathbf{R}_{\mathbf{t}}(\min )$ & $\begin{array}{l}\text { Molecular } \\
\text { Formula }\end{array}$ & $m / z$ obs. & $\begin{array}{c}\text { Error } \\
(\mathrm{ppm})\end{array}$ & MS/MS Fragments \\
\hline 1 & 12.57 & $\mathrm{C}_{27} \mathrm{H}_{42} \mathrm{O}_{2}$ & $\begin{array}{l}399.3245 \\
{[\mathrm{M}+\mathrm{H}]^{+}}\end{array}$ & 0.6 & $\begin{array}{c}71.0491,127.1117,255.2107 \\
381.3152\end{array}$ \\
\hline 2 & 13.39 & $\mathrm{C}_{27} \mathrm{H}_{42} \mathrm{O}$ & $\begin{array}{l}383.3304 \\
{[\mathrm{M}+\mathrm{H}]^{+}}\end{array}$ & 0.6 & $\begin{array}{l}107.0851,109.0648,133.0648 \\
147.1777,161.0961,175.1117\end{array}$ \\
\hline 3 & 9.80 & $\mathrm{C}_{29} \mathrm{H}_{46} \mathrm{O}_{2}$ & $\begin{array}{l}427.3573 \\
{[\mathrm{M}+\mathrm{H}]^{+}}\end{array}$ & 1.3 & $\begin{array}{c}81.0699,109.0648,137.0598, \\
273.1849\end{array}$ \\
\hline 4 & 10.13 & $\mathrm{C}_{29} \mathrm{H}_{46} \mathrm{O}_{3}$ & $\begin{array}{l}443.3519 \\
{[\mathrm{M}+\mathrm{H}]^{+}}\end{array}$ & 0.6 & $\begin{array}{l}81.0699,109.0648,161.0961 \\
267.2475,315.2682,425.3414\end{array}$ \\
\hline 5 & 6.09 & $\mathrm{C}_{27} \mathrm{H}_{50} \mathrm{O}_{12} \mathrm{~S}$ & $\begin{array}{l}597.2954 \\
{[\mathrm{M}-\mathrm{H}]^{-}}\end{array}$ & 0.6 & 225.0056 \\
\hline 6 & 9.53 & $\mathrm{C}_{25} \mathrm{H}_{48} \mathrm{O}_{11} \mathrm{~S}$ & $\begin{array}{l}555.2843 \\
{[\mathrm{M}-\mathrm{H}]^{-}}\end{array}$ & 0.3 & 225.0075 \\
\hline 7 & 13.16 & $\mathrm{C}_{27} \mathrm{H}_{52} \mathrm{O}_{11} \mathrm{~S}$ & $\begin{array}{l}583.3154 \\
{[\mathrm{M}-\mathrm{H}]^{-}}\end{array}$ & 0.6 & 225.0056 \\
\hline 8 & 8.92 & $\mathrm{C}_{18} \mathrm{H}_{34} \mathrm{O}_{3}$ & $\begin{array}{l}297.2430 \\
{[\mathrm{M}-\mathrm{H}]^{-}}\end{array}$ & 1.7 & $155.1078,171.1027,279.2330$ \\
\hline 9 & 13.04 & $\mathrm{C}_{16} \mathrm{H}_{32} \mathrm{O}_{2}$ & $\begin{array}{l}255.2328 \\
{[\mathrm{M}-\mathrm{H}]^{-}}\end{array}$ & 0.6 & 255.2330 \\
\hline
\end{tabular}




\subsection{Clinical Manifestation of Relief from Chronic Colitis Owing to TOE}

The effectiveness of the standardized M2 fraction of T. ornata (TOE) against chronic colitis was evaluated in DSS-induced C57BL/6 mice. All experimental animals were observed carefully for their clinical signs and weighed daily for 6 weeks. The mean body weight of the colitis induction groups decreased sharply in the first cycle of DSS + water supply. Contrary to our expectations, both clinical signs and degree of weight loss of the DSS + treatment groups (colitis, colitis + 5-ASA, colitis + TOE groups) were minimized in the second cycle, but not in the third cycle (Figure 4). The DAI graph showed three clear peaks: the first peak was the highest, the second peak was the smallest, and the third peak appeared as an intermediate value. According to our scoring system, the DAI of mice in the normal group was normalized to the zero point, so that it was not visible on the graph (Figure 5A). For a comprehensive evaluation of clinical symptoms of colitis throughout the experimental period, DAI scores were converted to DAI area under the curve (AUC). The AUC of the colitis + TOE group was lower $(33.07 \pm 9.91)$ than that of the colitis group $(72.62 \pm 31.48)$. The DAI AUC of the 5-ASA group was also lower $(46.50 \pm 13.44)$ than that of the colitis group, although the difference was not significant (Figure 5B).

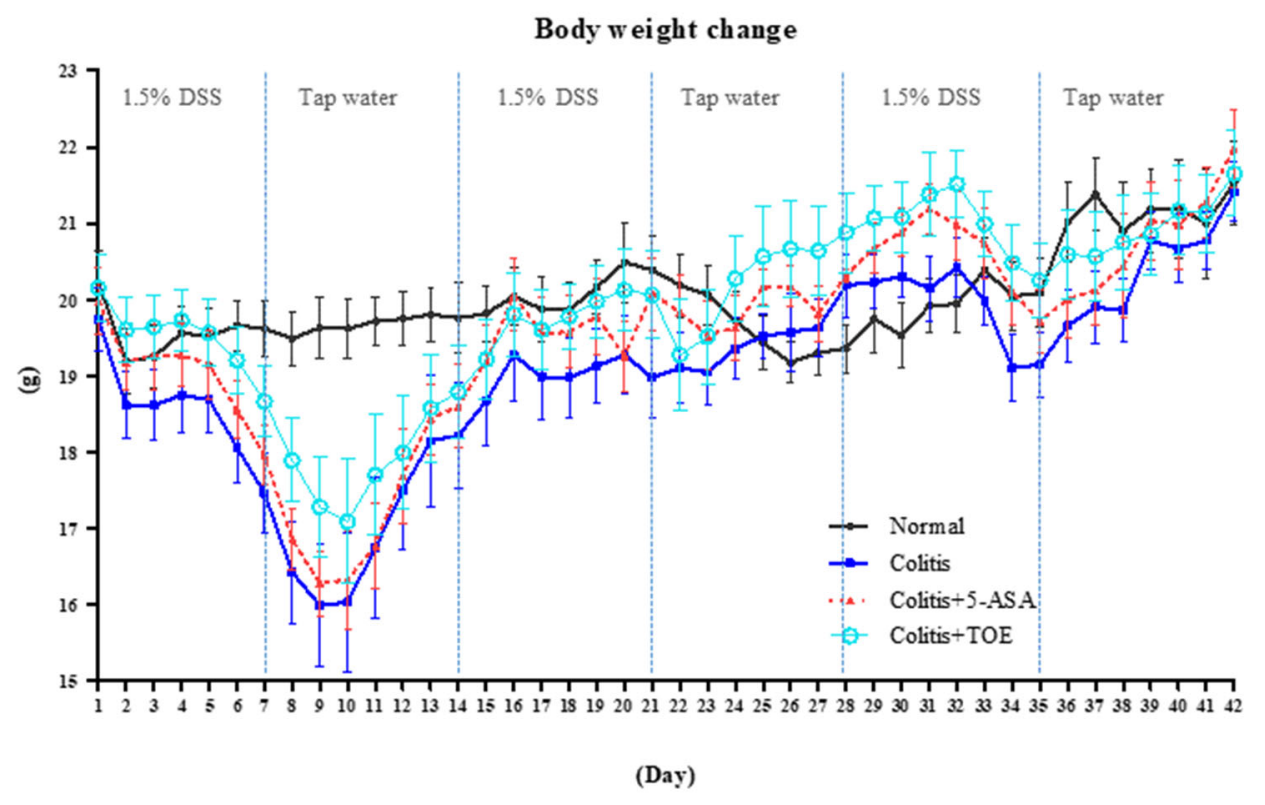

Figure 4. Effect of M2 fraction of Turbinaria ornata extract (TOE) on body weight in C57BL/6 mice with dextran sulfate sodium (DSS)-induced chronic colitis. The body weight of each mouse was measured daily. The values are presented as the mean body weight of each group \pm SD. Normal, DSS-/D.W; colitis, DSS + /D.W, colitis + 5-aminosalicylic acid (5-ASA), DSS + /5-ASA $50 \mathrm{mg}$ per kg; colitis + TOE, DSS + /TOE $15 \mathrm{mg}$ per $\mathrm{kg}$. 


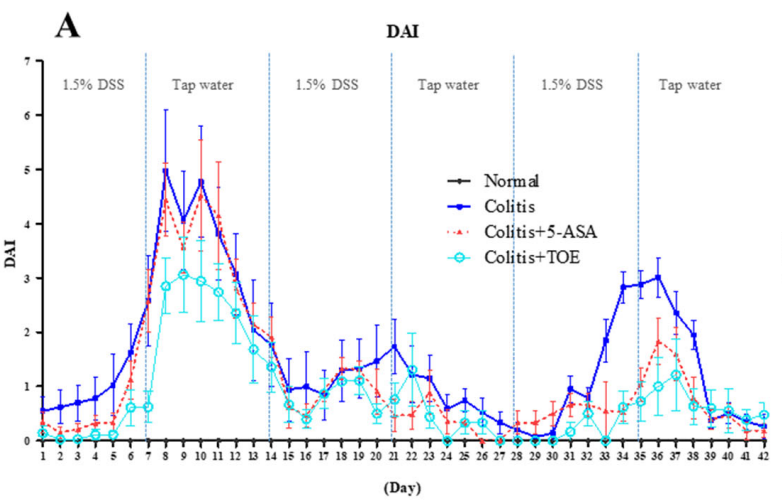

B

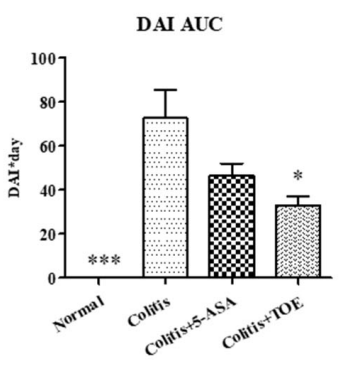

Figure 5. Effect of M2 fraction of Turbinaria ornata extract (TOE) on clinical severity of DSS-induced chronic colitis in C57BL/6 mice. (A) Disease activity index (DAI) score (B) DAI area under the curve (AUC) graph. ${ }^{*} p<0.05,{ }^{* * *} p<0.001$, compared with the colitis group. Normal, DSS-/D.W; Colitis, DSS + /D.W, Colitis + 5-ASA, DSS + /5-ASA 50 mg per kg; Colitis + TOE, DSS + /TOE 15 mg per kg.

\subsection{TOE Alleviates Gross and Microscopic Chronic Colitis Lesions}

After euthanizing all animals, the colons were quickly collected and measured. The mean length of the colon from the colitis + TOE $(6.53 \pm 0.14 \mathrm{~cm})$ and colitis + 5-ASA $(6.57 \pm 0.33 \mathrm{~cm})$ groups was significantly longer than that from the colitis group $(5.9 \pm 0.13 \mathrm{~cm})$. Normal colons showed the highest value $(7.15 \pm 0.34 \mathrm{~cm}$ ) (Figure 6A,B). Histopathologic examination revealed that 42 days of $1.5 \%$ DSS and water interval cycle resulted in chronic colitis lesions, showing typical abnormally proliferated epithelium with mononuclear and/or lymphoid cell infiltration, mottled fibrotic change, and mural thickening, mainly affecting the middle and distal parts of the colon. In the colitis + 5-ASA or colitis + TOE groups, the severe lesions were less common in the colons than those in the colitis group (Figure 6C). Specifically, the histopathological score $(3.63 \pm 1.51)$ in the colitis + TOE group was significantly lower than that in the colitis group (6.38 \pm 1.3$)$. The scores of the colitis + 5-ASA group $(4.86 \pm 1.07)$ also showed a similar trend. Normal healthy colons showed only minor mononuclear cells in the epithelium $(0.25 \pm 0.46)$ (Figure 6D).
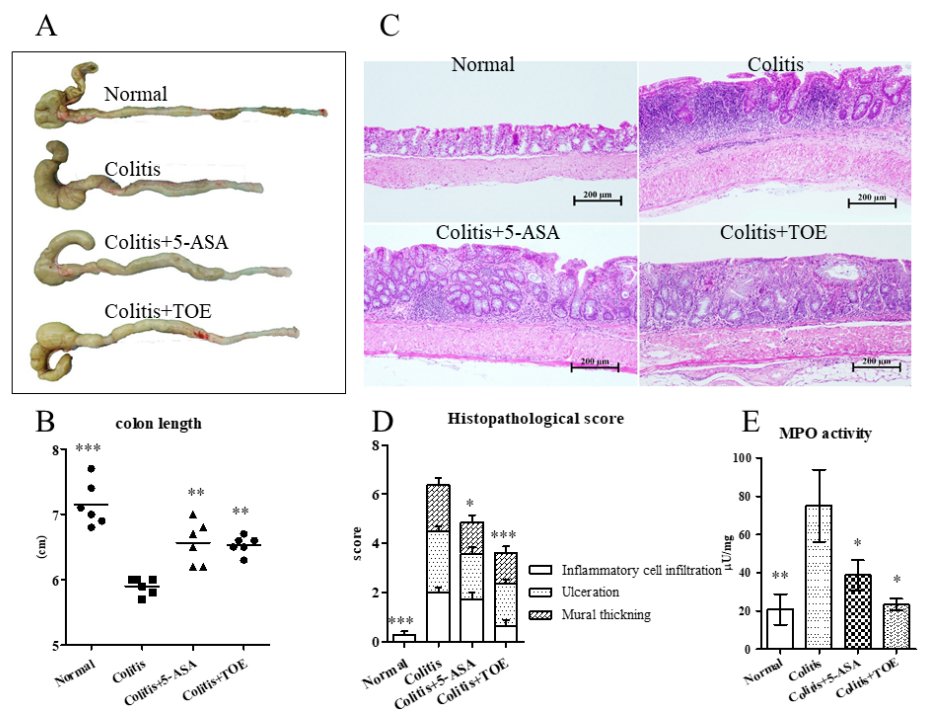

Figure 6. Effect of M2 fraction of Turbinaria ornata extract (TOE) on gross and microscopic examination of DSS-induced chronic colitis in C57BL/6 mice. (A) Gross lesions of colitis. (B) Colon length. (C) Microscopic examinations of hematoxylin and eosin (H\&E) stained colon tissues ( $\times 10$ magnification, bar $=200 \mu \mathrm{m}$ ). (D) Histopathological scores of colitis. (E) Myeloperoxidase (MPO) activity of colon tissue lysates. ${ }^{*} p<0.05,{ }^{* *} p<0.01,{ }^{* * *} p<0.001$, compared with the colitis group. Normal, DSS-/D.W; colitis, DSS + /D.W, colitis + 5-ASA, DSS + /5-ASA 50 mg per kg; colitis + TOE, DSS + /TOE 15 mg per kg. 


\subsection{TOE Reduced MPO Activity and COX-2 and TNF- $\alpha$ Expression in Chronic Colitis}

Regarding neutrophilic activity, all DSS-induced colitis groups showed increased MPO activity in colon tissue lysate. MPO activity of the colitis group $(75.00 \pm 37.80 \mu \mathrm{U} / \mathrm{mg})$ recorded the highest value, whereas that of colitis + 5-ASA $(38.69 \pm 15.95 \mu \mathrm{U} / \mathrm{mg})$ and colitis + TOE $(23.34 \pm 6.02 \mu \mathrm{U} / \mathrm{mg})$ decreased. MPO activity in the normal colon was only $20.79 \pm 14.95 \mu \mathrm{U} / \mathrm{mg}$. These figures were statistically significant (Figure 6E). Exploration of the general inflammatory markers in colitis using western blot, showed that COX-2 and TNF- $\alpha$ expression in both colitis + 5-ASA and colitis + TOE groups was markedly diminished compared to that in the colitis group (Figure 7, Figure 8A,C).

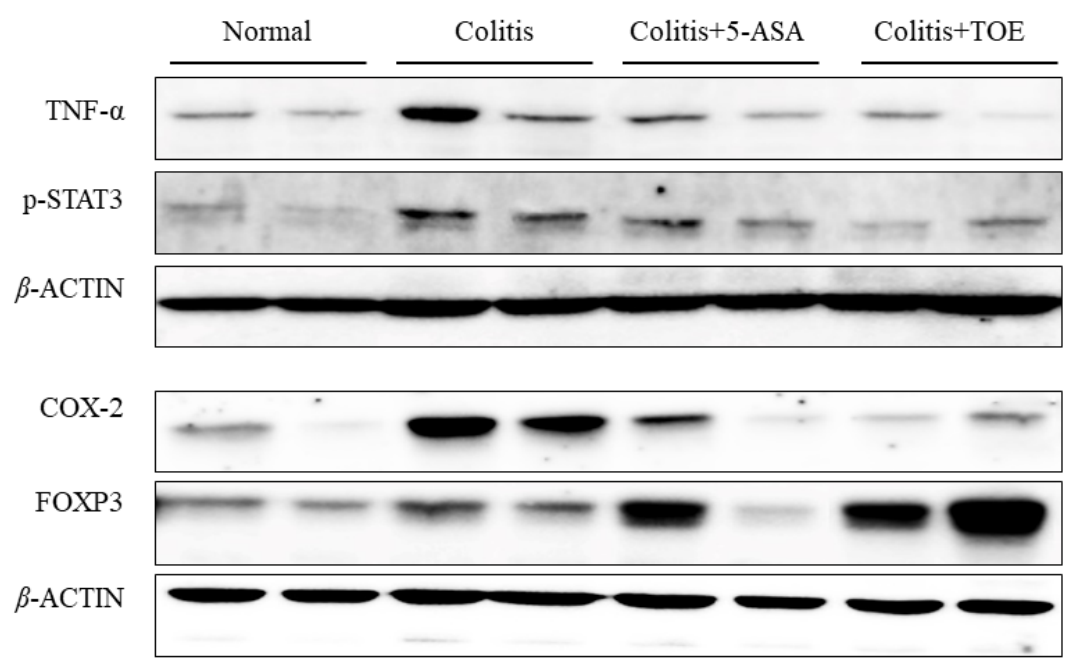

Figure 7. Effect of M2 fraction of Turbinaria ornata extract (TOE) on inflammatory markers and cytokines determined in chronic colitis tissues with western blotting. Six animal samples (colon lysates) per group were analyzed in duplicate. Normal, DSS-/D.W; colitis, DSS + /D.W, colitis + 5-ASA, DSS + /5-ASA $50 \mathrm{mg}$ per kg; colitis + TOE, DSS + /TOE $15 \mathrm{mg}$ per kg.
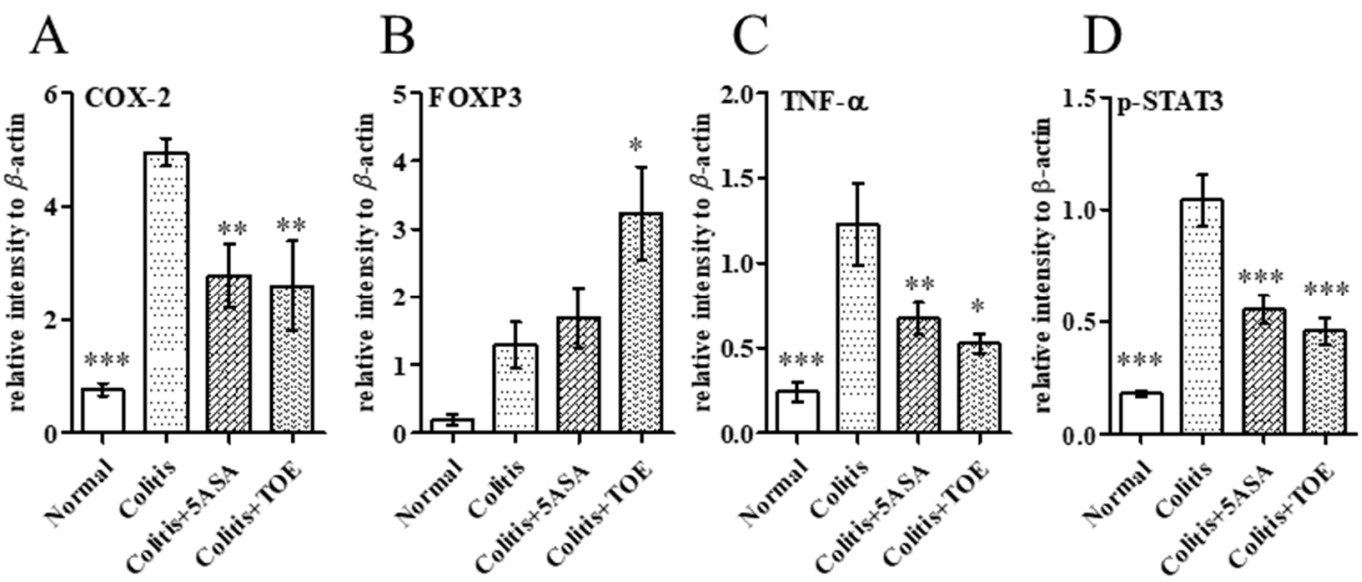

Figure 8. Relative intensity of protein expression levels in chronic colitis tissues of C57BL/6 mice determined using western blotting. (A) Cyclooxygenase-2 (COX-2), (B) forkhead box P3 (FOXP3), (C) tumor necrosis factor alpha (TNF- $\alpha$ ), (D) phosphorylated signal transducer and activator of transcription-3 (p-STAT3). ${ }^{*} p<0.05,{ }^{* *} p<0.01,{ }^{* * *} p<0.001$, compared with the colitis group. Normal, DSS-/D.W; colitis, DSS + /D.W, colitis + 5-ASA, DSS + /5-ASA 50 mg per kg; colitis + TOE, DSS + /TOE $15 \mathrm{mg}$ per $\mathrm{kg}$.

\subsection{TOE Administration Induced FOXP3+ Treg Cell Response in Chronic Colitis}

There were some discrete changes in the regulatory markers of inflammation observed during this study. It was found that a statistically high level of FOXP3 protein was expressed in the colon of 
the colitis + TOE group (Figures 7 and 8B). We also examined the Th17 reaction of p-STAT3 expression, confirming that FOXP3 overexpression was concomitant with Th17 downregulation. Western blot analysis showed that p-STAT3 expression was significantly decreased in the colon tissues of the colitis + TOE group (Figures 7 and 8D). We also tested for IL-17 and IL-10 antibodies using western blotting, although they were not detected in this study (data not shown).

\subsection{TOE Administration Altered Th1, Th2, Th17 and Treg Subsets and Cytokine mRNA Expression in Chronic Colitis}

After confirming the opposing expression of high FOXP3 and low p-STAT3 in the colon with TOE treatment, the major subsets of helper T cells and related cytokine mRNA expression levels were examined using qPCR. The results showed that Th1 and Th2 transcription factors (T-bet and Gata3, respectively) were greatly increased; however, related cytokines such as Ifn- $\gamma$ and Il-4 did not show significant changes after TOE administration (Figure 9A,B,E,F). In contrast, the Th17 transcription factor Ror $\gamma t$ and Il-17 mRNAs were somewhat diminished, although not significantly (Figure 9C,G). Treg specific Foxp3 and Il-10 mRNA expression levels were remarkably elevated (Figure 9D,H). Tnf- $\alpha$, which is a cytokine related to both macrophages and the Th1 subset, also exhibited a sharp decline in mRNA level (Figure 9I). These results were comparable with those of the western blot analysis. In addition, Il-6, which is another important pro-inflammatory cytokine in IBD, decreased in the colitis + TOE group, although the difference was not significant (Figure 9J). We also examined the pan T cell marker Cd3 mRNA, which showed no change in all DSS-induced colitis groups (Figure 9K).
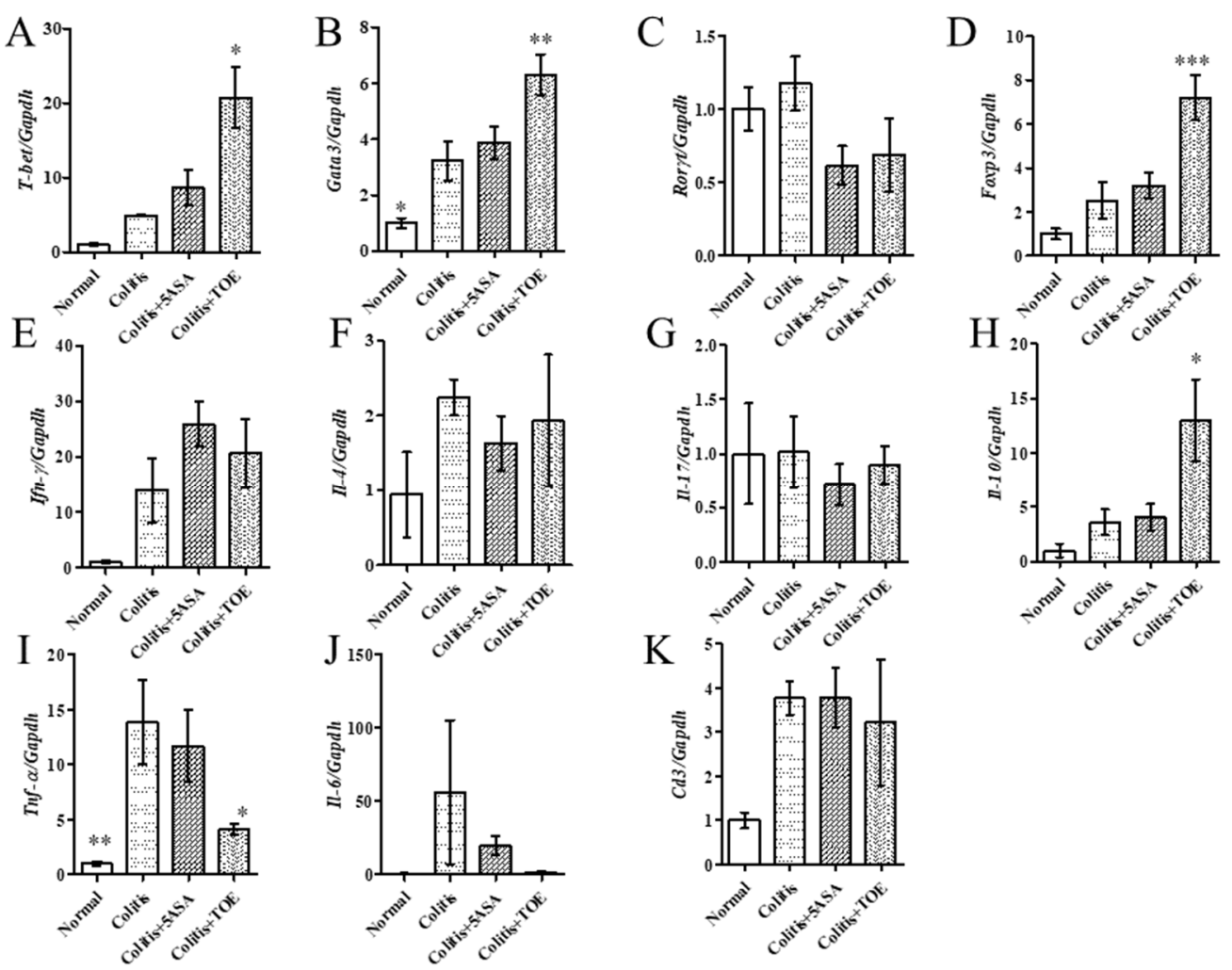

Figure 9. Effect of Turbinaria ornata extract (TOE) on helper T cell subsets markers and related cytokine mRNA expression levels in chronic colitis tissues of C57BL/6 mice. (A) T-bet (B) Gata3 (C) Ror $\gamma t$ (D) Foxp3 (E) Ifn- $\gamma$ (F) Il-4 (G) Il-17 (H) Il-10 (I) Tnf- $\alpha$ (J) Il-6 (K) Cd3. ${ }^{*} p<0.05,{ }^{* *} p<0.01,{ }^{* * *} p<0.001$, compared with the colitis group. Normal, DSS-/D.W; colitis, DSS + /D.W, colitis + 5-ASA, DSS + /5-ASA $50 \mathrm{mg}$ per $\mathrm{kg}$; colitis + TOE, DSS + /TOE $15 \mathrm{mg}$ per kg. 


\section{Discussion}

T. ornata is an edible brown alga (seaweed) that is common worldwide. Research on the anti-inflammatory potential of T. ornata has been limited. The inhibitory effect on cotton pellet induced by granuloma was the first report to investigate the anti-inflammatory effect of T. ornate [27]. Recently, our research team reported the anti-inflammatory effect of $T$. ornata in an in vitro model of IBD comprising human epithelial Caco-2 and THP-1 macrophages [28]. Sulfoquinovosyl monoacylglycerols and steroids were identified in the extract of T. ornata. Among the isolated compounds, sulfoquinovosyl monoacylglycerols that possess carbon chains of C18 (compounds $\mathbf{5}$ and $\mathbf{7}$ in this study) were found to be biologically active metabolites that inhibit the expression of inflammatory proteins and nucleic translocation of NF- $\mathrm{KB}$ [28]. In the present study, the chemical profile of TOE was deduced through LC-QTOF-MS analysis. It was observed that TOE mainly contained steroids and sulfoquinovosyl monoacylglycerols, which were detected in the positive and negative mode, respectively. We attempted to investigate the in vivo therapeutic effect of TOE, including that of these bioactive metabolites, using an animal model of UC.

First, 6 weeks of TOE treatment $(15 \mathrm{mg} / \mathrm{kg})$ in chronic colitis-induced C57BL/6 mice showed marked clinical improvement. Body weight loss in the TOE-treated group was minimal compared with that in the colitis or colitis + 5-ASA groups. The DAI score, the quantified data of clinical manifestation of colitis, was significantly lower in the colitis + TOE group than that in the colitis group. The clinical improvements were also obvious in the results of autopsy and microscopy investigations. Shortening in colon length was protected with TOE administration, and further histopathological evaluation concluded that TOE administration alleviated lesions owing to chronic colitis. These in vivo results strongly suggest that TOE is effective in preventing UC.

To understand how TOE influences the anti-inflammatory effect, the expression of some common pro-inflammatory markers was monitored in the colon tissues. MPO is one of the most abundant peroxidation enzymes in neutrophils, but is less in monocytes [36]. It is released from activated neutrophils into the extracellular matrix and directly causes epithelial death and tissue damage [36]. Thus, measuring MPO activity in colitis tissue is an effective method to estimate the extent of neutrophil infiltration. In this study, TOE-treated colon tissue showed less MPO activity, which means that TOE can directly reduce neutrophilic inflammation in the colonic mucosa.

There is also a potent inflammatory mediator, COX-2, which is induced by several stimuli such as lipopolysaccharide (LPS), TNF- $\alpha$, and IL-1, and converts arachidonic acid to strong inflammatory mediators such as prostaglandins, prostacyclin, and thromboxane [37]. COX-2 was chosen for this study because it is barely expressed in the normal state but is upregulated in inflamed mucosa and in colitis tissues [37]. In addition, a recent study suggested a new insight into the pathogenesis of UC. At the initiation of colitis, colonic epithelium-specific mammalian target of rapamycin complex 1 induces COX-2 via p-STAT3, which then mediates the Th-17 response [38]. The pro-inflammatory cytokine TNF- $\alpha$, which is another noticeable target of biological agents of UC such as infliximab, adalimumab, and golimumab was also analyzed [39]. The present study revealed that TOE administration led to a dramatic reduction in both COX-2 and TNF- $\alpha$ expression. These results confirmed that TOE has potent anti-inflammatory effects.

Among the investigated mechanisms of the anti-inflammatory effect of TOE, remarkable changes in $\mathrm{CD}^{+} \mathrm{T}$ cell subsets expression levels were observed. In UC, regulation of pro-inflammatory Th1, Th2, and Th17 cells and induction of Treg subsets are the key targets for colitis treatment [40]. Treg subsets are induced by TGF- $\beta$, express FOXP3, and produce IL-10 [11,12]. FOXP3 is not only a specific marker of both naturally occurring Tregs and induced Tregs, but is also necessary and sufficient for the immunosuppressive activity of Treg cells [41,42]. Treg cells play important roles in alleviating colitis. It limits both effector $T$ cells and the innate inflammatory response [15]. It plays a pivotal role in the inhibition of a broad range of inflammation. There are four key mechanisms by which Tregs suppress the immune response: (1) secretion of the anti-inflammatory cytokine IL-10 (2) CD28 family (such as (cytotoxic T-lymphocyte-associated protein 4, CTLA-4 and programmed cell death protein 
1, PD-1)) and CD25 surface molecule signaling, (3) cytotoxic activity, and (4) metabolic control [43]. In a previous study, IL-10 was demonstrated to be a potent inhibitor of the production of IL- $1 \alpha$, IL-6, IL-8, and TNF- $\alpha$ by human monocytes and macrophages [44]. TOE administration led to a significant increase in FOXP3 and IL-10 expression, which indicates the manifestation of Treg activity.

Among the Janus kinase/STAT pathway molecules, STAT3 is a widely known transducer that produces several pro-inflammatory cytokines; interferons, TNF- $\alpha$, and IL-6; it is essential for Th17 differentiation, and its activation is closely related to IBD [17]. In the western blot analysis, colons that were treated with TOE showed decreased p-STAT3 expression, whereas FOXP3 expression was increased. This result explains how TOE reduces chronic colitis. In addition, 5-ASA treatment could not induce FOXP3, but down-regulated p-STAT3.

In colitis, continued stimulation of IL-6 activates STAT3 signaling, and is prone to modulating the Th17/Treg immune balance owing to Th17 responses [45]. Therefore, the decrease in both IL-6 and p-STAT3 was additional evidence that TOE is involved in the regulation of immune balance through reducing Th17 activity. Unfortunately, our analysis failed to detect IL-17 and IL-10 proteins, which are effector cytokines of Th17 and Treg, respectively. It is speculated that an insufficient amount of tissues was tested so that the content of these markers might have been under the detection limit of western blotting. These cytokines were detected by qPCR analysis and a significant increase in Il-10 mRNA expression was observed.

In contrast, some inconsistencies were found regarding our expectations: (1) there was no alteration in Ror $\gamma t$ and Il-17 mRNA expression in the colitis + TOE group, whereas an increment in Foxp3, Il-10, and reduction in Il-6 and p-STAT3. At the beginning of this study, we assumed that activation of FOXP3 $3^{+}$Tregs leads to Th17 downregulation. These conflicting results may represent the existence of double-expressing cells: $\mathrm{ROR} \gamma \mathrm{T}^{+} \mathrm{FOXP}^{+}$or $\mathrm{IL}-17^{+} \mathrm{FOXP}^{+}$cells [15]. However, confirmation of the existence of these double positive cells requires performing flow cytometer on colonic lamina propria cells. (2) Interestingly, it is also incomprehensible that the Th1 transcription factor T-bet and Th2 transcription factor Gata3, were all significantly increased, whereas the secreted cytokines Ifn- $\gamma$ and Il-4 did not change or even decrease. These discrepancies are seldom reported; however, it might suggest that the administration of therapeutic agents (such as TOE) could have multifactorial functions. This phenomenon should certainly be investigated in further studies.

In conclusion, TOE is effective in preventing chronic colitis through the upregulation of $\mathrm{FOXP}^{+}$ Treg cells and its secreted anti-inflammatory cytokine, IL-10. It showed a reduction in TNF- $\alpha$, COX-2, and IL-6 followed by that in p-STAT3 as well as in MPO activity and histological lesions. All these palliative effects were closely related to Treg activation. Although it could not directly detect the IL-10 protein, Il-10 mRNA expression, and high levels of FOXP3 protein in colitis tissues would support the hypothesis that TOE could induce Tregs. However, further investigation using flow cytometry is needed to confirm the immune cell subpopulations.

\section{Materials and Methods}

\subsection{Preparation of the Fraction M2 from a Brown Algae T. ornata}

A brown algae T. ornata was collected at Fulhadhoo in Maldive in August 2017. The research sample was confirmed by Professor You-Jin Jeon at Jeju National University, South Korea. The sample $(3.0 \mathrm{Kg})$ was lyophilized and then was extracted with $90 \%$ aqueous EtOH (2 L) twice at room temperature. The extracts were concentrated in vacuo and suspended with water $(1.5 \mathrm{~L})$. Following this, the aqueous layer was sequentially partitioned with hexane $(1 \mathrm{~L}), \mathrm{CHCl}_{3}(1 \mathrm{~L})$, ethyl acetate $(1 \mathrm{~L})$ and $\mathrm{BuOH}(0.7 \mathrm{~L})$. The $\mathrm{BuOH}$-soluble part $(1 \mathrm{~g})$ was subjected to column $(3 \times 100 \mathrm{~cm})$ chromatography with Sephadex LH-20, eluted with 100\% MeOH to yield four fractions (M1 M4). Fraction M2 (230 mg) prepared via elution from 50 to $60 \mathrm{~min}$ at a flow rate of $1.0 \mathrm{~mL} / \mathrm{min}$ showed good activity in NO and IL-10 inhibition assays referred to TOE. TOE was concentrated in vacuo and freeze dried. For administration of TOE to animals, the fraction was weighed accurately and suspended in $0.5 \%$-carboxymethyl cellulose (CMC). 


\subsection{Isolation of Sulfoquinovosylglycerols and Steroids from T. ornata}

Bioactive fraction M2 was separated into three major fractions by HPLC using a column YMC ODS-A $250 \times 10 \mathrm{~mm}$, isocratic eluting solvent of $95 \%$ aq. $\mathrm{MeOH}$ including $0.1 \%$ formic acid, and refractive index detector. The first fraction (Fr.1, $40 \mathrm{mg}$ ) at the retention time of $6.5 \mathrm{~min}$ was separated to yield compounds $5(2.1 \mathrm{mg}), 6(1.2 \mathrm{mg})$ and $7(5.4 \mathrm{mg})$ using gradient HPLC method [column: Phenomenex C8 $250 \times 4.6 \mathrm{~mm}$, flow rate: $1.0 \mathrm{~mL} / \mathrm{min}, \mathrm{A}: \mathrm{H}_{2} \mathrm{O}$ with $0.1 \%$ formic acid, $\mathrm{B}: \mathrm{ACN}$, $20 \%$ ACN linearly increase to $100 \% \mathrm{ACN}$ for $20 \mathrm{~min}$, detector: ELSD]. Other two fractions (Fr.2, $15 \mathrm{mg}$ and Fr.3, $80 \mathrm{mg}$ ) at a retention time of 19 21 min were separated into a steroid compound 1 (5.0 $\mathrm{mg})$. Further purification by HPLC was conducted by a YMC ODS-A $(250 \times 10 \mathrm{~mm})$ column eluting $95 \%$ aq. ACN solvent.

\subsection{LC-MS Analysis}

A HPLC ExionLC (SCIEX, Framingham, MA, USA) coupled to a quadruple time-of-flight X500R mass spectrometer (SCIEX, Framingham, MA, USA) was used for LC-MS analysis. The sample separation was performed on a Kinetex C18 column $(50 \mathrm{~mm} \times 2.1 \mathrm{~mm}, 2.6 \mu \mathrm{m})$ (Phenomenex, Torrance, CA, USA). The HPLC solvents were composed of ultrapure water containing $0.1 \%(v / v)$ formic acid and acetonitrile, indicating solvent $A$ and $B$, respectively. The two eluting solvents were mixed in a gradient way, which $30 \%$ solvent B was linearly increased to $100 \%$ solvent B for 15 min with a flow rate of $0.2 \mathrm{~mL} / \mathrm{min}$. The electrospray ionization (ESI) source of the MS and MS/MS in positive mode was operated as follows: IonSpray voltage $5500 \mathrm{~V}$; curtain gas 30 psi; ion source gas 150 psi; ion source gas 250 psi; declustering potential $80 \mathrm{~V}$; temperature $550{ }^{\circ} \mathrm{C}$; collision energy $35 \pm 15 \mathrm{~V}$. The mass ranges were $m / z$ 100 1500 for QTOF MS and m/z 50 1500 for MS/MS. The MS/MS spectra was obtained by the information-dependent acquisition (IDA). The parameters for the MS and MS/MS spectra in negative mode are nearly same except for IonSpray voltage $-4500 \mathrm{~V}$; declustering potential $-80 \mathrm{~V}$; collision energy $-35 \pm 15 \mathrm{~V}$. The calibration of molecular weight was followed by every 5 samples. The acquired MS and MS/MS data were analyzed by SCIEX OS 1.6.1 software (SCIEX, Framingham, MA, USA).

\subsection{Experimental Animals}

Seven-week old female C57BL/6J mice were purchased from Japan SLC, Inc. (Hamamatsu, Japan). All mice were housed in controlled temperature $\left(20 \sim 27^{\circ} \mathrm{C}\right)$ and $12 \mathrm{~h} / 12 \mathrm{~h}$ light/dark cycle, and standard rodent chow pellets and reverse osmosis filtered water were fed freely. After 2 weeks of acclimation period, animals were randomly divided into six mice per group $(n=6)$ and placed wire cages individually. Animal care and experimental protocols were approved by the Institutional Animal Care and Use Committee at Gyeongnam Department of Environmental and Chemistry, Korea Institute of Toxicity.

\subsection{DSS-Induced Chronic Colitis and Treatment Protocol}

Chronic colitis was induced by three cycles of 1.5\% DSS (MP Biomedicals) in drinking water ad libitum for 7 days followed by 7 day of recovery, referred to the previous publication [46]. Normal control group were given tap water without DSS for same experimental period. Samples were administered by oral route once daily. There were 4 groups in this experiments; (i) normal: DSS-/D.W), (ii) colitis: DSS + /D.W), (iii) colitis + 5-ASA: DSS + /5-ASA 50 mg per kg), and (iv) colitis + TOE: DSS + /TOE $15 \mathrm{mg}$ per $\mathrm{kg})$ group $(n=6)$.

\subsection{Body Weight Change and DAI Score}

All animals were carefully monitored its clinical symptoms and weighed every day. For evaluation of DAI, body weight change, stool consistency and blood in feces were observed and scored by minor modification of the previous study [40] as follows; body weight change (no change or gain $=0$, 
$\leq 5 \%=1,6 \sim 10 \%=2,11 \sim 15 \%=3, \geq 15 \%=4$ ), stool consistency (normal $=0$, soft but remain formed stool $=1$, diarrhea $=2$ ), blood in feces (negative $=0$, positive $=2$ ). The DAI was calculated through all experimental day and its changes over time demonstrated by area under the curve (AUC).

\subsection{Colon Length Measurements and Histopathologic Evaluation}

At the end of the treatment, animals were euthanized by $\mathrm{CO}_{2}$ chamber and blood was collected immediately from the abdominal aorta. The colon length between the cecum to the anus was measured and dissected longitudinally, three equal strips. One of them was fixed with $10 \%$ neutral buffered formalin solution for hematoxylin and eosin (H\&E) staining, and others were stored at $-72{ }^{\circ} \mathrm{C}$ deep freezer for other analysis. Histopathologic examination of colon tissues was performed based on the grading systems of previous publications; inflammatory cells infiltration, ulceration, and mural thickening $(0=$ none, $1=$ mild, $2=$ moderate, $3=$ severe $)$.

\subsection{MPO Activity}

$\mathrm{MPO}$ activity assay was performed with OxiSelect ${ }^{\mathrm{TM}}$ myeloperoxidase peroxidation activity assay fluorometric kit (Cell Biolabs, San Diego, CA, USA). Briefly, frozen colon samples were homogenized cold $100 \mathrm{mM}$ phosphate buffer ( $\mathrm{pH}$ 6.0), containing 0.5\% HTAB. Centrifuge the homogenate at $12,000 \mathrm{rpm}$ for $15 \mathrm{~min}$ at $4{ }^{\circ} \mathrm{C}$. Then, collect the supernatant and 1:10 diluted with assay buffer, stored on ice. It was prepared that a set of standard, working solution, and MPO peroxidation solution. After loading $50 \mu \mathrm{L}$ of samples and controls and $50 \mu \mathrm{L}$ of reagents, immediately read the fluorescence of $544 \mathrm{~nm}$ excitation and $590 \mathrm{~nm}$ emission filter with microplate reader (Synergy H1, BioTek, Winooski, VT, USA), up to 30 min by kinetic methods. The results were calculated by the datasheet manual.

\subsection{Western Blot Analysis}

Protein extraction from the colon tissue was done by T-PER tissue protein extraction reagent (Thermo Fisher Scientific, Waltham, MA, USA). Equally loaded samples $(30 \mu \mathrm{g})$ were separated on 10\% SDS-PAGE gel and then transferred to the PVDF membrane by iBlotTM-2 transfer kit (Invitrogen, Waltham, MA, USA). Next, membranes were incubated with blocking solution for $1 \mathrm{~h}$ and done with primary antibody at $4{ }^{\circ} \mathrm{C}$ overnight; TNF- $\alpha$ (Abcam, Cambridge, UK), FOXP3 (Invitrogen, Carlsbad, CA, USA), COX-2 (Abcam, Cambridge, UK), and p-STAT3 (Cell signaling, Danvers, MA, USA) at 1:500 dilution. Washing three times with phosphate buffered saline with Tween 20 (PBST), all membranes were incubated with secondary horseradish peroxidase-linked anti-mouse or and-rabbit for $40 \mathrm{~min}$. After washing step, it was soaked in the enhanced chemiluminescence solution for up to one minute, and its signals were detected by ChemiDoc ${ }^{\mathrm{TM}}$ imaging system. Relative density of the bands was analyzed with Image Lab software (Bio-Rad, Berkeley, CA, USA).

\subsection{0. $R T-q P C R$}

Total RNA was isolated using QIAzol solution (Qiagen, Hilden, Germany), and then cDNA was synthesize with QuantiTect reverse transcription kit (Qiagen) according to the manufacturer's guideline. For the real-time PCR, a total of $50 \mu \mathrm{L}$ reaction mix constituted with $100 \mathrm{nM}$ of cDNA template, $10 \mathrm{pM}$ of each primers, and SYBR green master reagent (Go Taq, Promega, Madison, WI, USA) was prepared. Then, PCR was performed initial denaturation step at $95^{\circ} \mathrm{C}$ for $2 \mathrm{~min}$ followed by 40 cycles of $95^{\circ} \mathrm{C}$ for $15 \mathrm{~s}$ and $60^{\circ} \mathrm{C}$ for $60 \mathrm{~s}$ by the TP 950 thermal cycler (Takara Bio, Shiga, Japan). All samples were analyzed twice. The results were normalized with GAPDH and then calculated by $\Delta \Delta \mathrm{Ct}$ method. Primer sequences for this experiment were provided in Supplementary Materials S2.

\subsection{Statistical Analysis}

All statistical analysis was performed with SPSS statistics 17.0 program (SPSS Inc., Chicago, IL, USA), one-way ANOVA followed by Dunnett's post hoc test was for the data satisfied with Levene's 
test. Otherwise, non-parametric Kruskal-Wallis test with Dunn's test was performed. $p$ values of $<0.05$ were considered as significant. The results were converted to the graph by GraphPad Prism 5 (San Diego, CA, USA), which all columns of the graph had error bars denoted standard error of the mean.

Supplementary Materials: The following are available online at http://www.mdpi.com/2218-273X/10/10/1463/s1, S1: Inhibitory activities of fractions M1 M4 of T. ornata extract on nitric oxide and inflammatory cytokines in LPS-activated RAW264.7 cells, S2: Primer sequences for RT-qPCR.

Author Contributions: E.J.J. and N.-H.K. designed the experiments; E.J.J., J.-D.H., and J.-R.R. organized the project; S.M.L., Y.N.K., and N.-H.K. performed in vivo experiments; J.-R.R. performed isolation and NMR experiments; N.-H.K., Y.-J.J. identified and provided T. ornata resources; E.J.J., and J.-R.R. analyzed the data; E.J.J., J.-R.R., and N.-H.K. wrote the paper. All authors have read and agreed to the published version of the manuscript.

Funding: This research was funded by a grant from the Marine Biotechnology Program (20170488) funded by the Ministry of Oceans and Fisheries, Korea.

Conflicts of Interest: The authors declare no conflict of interest.

\section{Abbreviations}

$\begin{array}{ll}\text { IL } & \text { Interleukin } \\ \text { COX } & \text { Cyclooxygenase } \\ \text { DAI } & \text { disease activity index } \\ \text { FOXP3 } & \text { forkhead box P3 } \\ \text { GATA3 } & \text { GATA binding protein 3 } \\ \text { HRESIMS } & \text { High Resolution ElectroSpray Ionization Mass Spectrometry } \\ \text { IFN- } \gamma & \text { interferon gamma } \\ \text { LC-QTOF-MS } & \text { Liquid Chromatography Time-of-Flight Mass Spectrometry } \\ \text { MPO } & \text { Myeloperoxidase } \\ \text { NF-kB } & \text { nuclear factor kappa-light-chain-enhancer of activated B cells } \\ \text { Nrf2 } & \text { nuclear factor erythroid 2 related factor 2 } \\ \text { p-STAT3 } & \text { signal transducer and activator of transcription 3 } \\ \text { ROR } \gamma \text { T } & \text { retinoic-acid-receptor-related orphan nuclear receptor gamma } \\ \text { T-bet } & \text { T-box expressed in T cells } \\ \text { Th } & \text { T helper cells } \\ \text { TNF- } \alpha & \text { tumor necrosis factor alpha } \\ \text { Treg } & \text { regulatory T cells }\end{array}$

\section{References}

1. Molodecky, N.A.; Soon, S.; Rabi, D.M.; Ghali, W.A.; Ferris, M.; Chernoff, G.; Benchimol, E.I.; Panaccione, R.; Ghosh, S.; Barkema, H.W.; et al. Increasing incidence and prevalence of the inflammatory bowel diseases with time, based on systematic review. Gastroenterology 2012, 142, 46-54. [CrossRef] [PubMed]

2. De Kange, K.M.; Barrett, J.C. Understanding inflammatory bowel disease via immunogenetics. J. Autoimmun. 2015, 64, 91-100. [CrossRef]

3. Loftus, E.V., Jr.; Sandborn, W.J. Epidemiology of inflammatory bowel disease. Gastroenterol. Clin. N. Am. 2002, 312, 1-20. [CrossRef]

4. Bouma, G.; Strober, W. The immunological and genetic basis of inflammatory bowel disease. Nat. Rev. Immunol. 2003, 3, 521-533. [CrossRef] [PubMed]

5. Kaser, A.; Zeissig, S.; Blumberg, R.S. Inflammatory bowel disease. Annu. Rev. Immunol. 2010, $28,573-621$. [CrossRef]

6. Rutgeerts, P.; Vermeire, S.; Van Assche, G. Biological therapies for inflammatory bowel disease. Nature 2009, 136, 1182-1197. [CrossRef]

7. Yan, Y.; Kolachala, V.; Dalmasso, G.; Nguyen, H.; Laroui, H.; Sitaraman, S.V.; Merlin, D. Temporalandspatial analysis of clinical and molecular parameters in dextran sodium sulfate induced colitis. PLoS ONE 2009, 4, e6073. [CrossRef] 
8. Larmonier, C.B.K.W.; Shehab, F.K.; Kiela, P.R. T lymphocyte dynamics in inflammatory bowel diseases: Role of the microbiome. BioMed Res. Int. 2015, 2015, 504638. [CrossRef]

9. Ruder, B.; Atreya, R.; Becker, C. Tumour necrosis factor alpha in intestinal homeostasis and gut related diseases. Int. J. Mol. Sci. 2019, 20, 1887. [CrossRef]

10. Slebioda, T.J.; Kmiec, Z. Tumour necrosis factor superfamily members in the pathogenesis of inflammatory bowel disease. Mediat. Inflamm. 2014, 2014, 325129. [CrossRef]

11. Shale, M.; Schiering, C.; Powrie, F. CD4+ T-cell subsets in intestinal inflammation. Immunol. Rev. 2013, 252, 164-182. [CrossRef] [PubMed]

12. Cader, M.Z.; Kaser, A. Recent advances in inflammatory bowel disease: Mucosal immune cells in intestinal inflammation. Gut 2013, 62, 1653-1664. [CrossRef] [PubMed]

13. Yang, G.; Yifan, L.; Ning, Z.; Xiaojuan, H.; Aiping, L.; Wie, W.; Miao, J. The Th17/Treg immune imbalance in ulcerative colitis disease in a Chinese Han Population. Mediat. Inflamm. 2016, 2016, 7089137.

14. Brand, S. Crohn's disease: Th1, Th17 or both? The change of a paradigm: New immunological and genetic insights implicate Th17 cells in the pathogenesis of Crohn's disease. Gut 2009, 58, 1152-1167. [CrossRef] [PubMed]

15. Ueno, A.; Jeffery, L.; Kobayashi, T.; Hibi, T.; Ghosh, S.; Jijon, H. Th17 plasticity and its relevance to inflammatory bowel disease. J. Autoimm. 2018, 87, 38-49. [CrossRef] [PubMed]

16. Sabatino, A.; Di Lenti, M.V.; Giuffrida, P.; Vanoli, A.; Corazza, G.R. New insights into immune mechanisms underlying autoimmune diseases of the gastrointestinal tract. Autoimmun. Rev. 2015, 14, 1161-1169. [CrossRef] [PubMed]

17. Kasembeli, M.M.; Bharadwaj, U.; Robinson, P.; Tweardy, D.J. Contribution of STAT3 to inflammatory and fibrotic diseases and prospects for its targeting for treatment. Int. J. Mol. Sci. 2018, 19, 2299. [CrossRef] [PubMed]

18. Lovato, P.; Brender, C.; Agnholt, J.; Kelsen, J.; Kaltoft, K.; Svejgaard, A.; Eriksen, K.W.; Woetmann, A.; Ødum, N. Constitutive STAT3 activation in intestinal T cells from patients with Crohn's disease. J. Biol. Chem. 2003, 278, 16777-16781. [CrossRef]

19. Baumgart, D.C.; Sandborn, W.J. Inflammatory bowel disease: Clinical aspects and established and evolving therapies. Lancet 2007, 369, 1641-1657. [CrossRef]

20. Saxena, A.; Kaur, K.; Hegde, S.; Kalekhan, F.M.; Baliga, M.S.; Fayad, R. Dietary agents and phytochemicals in the prevention and treatment of experimental ulcerative colitis. J. Tradit. Complement. Med. 2014, 4, $203-217$. [CrossRef]

21. Lean, Q.Y.; Eri, R.D.; Fitton, J.H.; Patel, R.P.; Gueven, N. Fucoidan extracts ameliorate acute colitis. PLoS ONE 2015, 10, e0128453. [CrossRef] [PubMed]

22. Miceli, M.; Bontempo, P.; Nebbioso, A.; Altucci, L. Natural compounds in epigenetics: A current view. Food Chem. Toxicol. 2014, 73, 71-83. [CrossRef]

23. Asari, F.; Kusumi, T.; Kakisawa, H. Turbinaric acid, a cytotoxic secosqualene carboxylic acid from the brown alga Turbinaria ornata. J. Nat. Prod. 1989, 52, 1167-1169. [CrossRef] [PubMed]

24. Sheu, J.; Wang, G.; Sung, P.; Chiu, Y.; Duh, C. Cytotoxic sterols from the Formosan brown alga Turbinaria ornata. Planta Med. 1997, 63, 571-572. [CrossRef] [PubMed]

25. Zubia, M.; Payri, C.; Deslandes, E. Alginate, mannitol, phenolic compounds and biological activities of two range-extending brown algae, Sargassum mangarevense and Turbinaria ornata (Phaeophyta: Fucales), from Tahiti (French Polynesia). J. Appl. Phycol. 2008, 20, 1033-1043. [CrossRef]

26. Vijayabaskar, P.; Shiyamala, V. Antioxidant properties of seaweed polyphenol from Turbinaria ornata (Turner) J. Agardh, 1848. Asian Pac. J. Trop. Biomed. 2012, 2, S90-S98. [CrossRef]

27. Subash, A.; Veeraraghavan, G.; Sali, V.K.; Bhardwaj, M.; Vasanthi, H.R. Attenuation of inflammation by marine algae Turbinaria ornata in cotton pellet induced granuloma mediated by fucoidan like sulphated polysaccharide. Carbohydr. Polym. 2016, 151, 1261-1268. [CrossRef]

28. Lee, S.M.; Kim, N.-H.; Ji, Y.K.; Kim, Y.N.; Jeon, Y.-J.; Heo, J.D.; Jeong, E.J.; Rho, J.-R. Sulfoquinovosylmonoacylglycerols regulating intestinal inflammation in co-culture system from the brown alga Turbinaria ornata. Alage 2020, 35, 201-212. [CrossRef]

29. Wirtz, S.; Neufert, C.; Weigmann, B.; Neurath, M.F. Chemically induced mouse models of intestinal inflammation. Nat. Protoc. 2007, 2, 541-546. [CrossRef] 
30. Elson, C.O.; Sartor, R.B.; Tennyson, G.S.; Riddell, R.H. Experimental models of inflammatory bowel disease. Gastroenterology 1995, 109, 1344-1367. [CrossRef]

31. Perše, M.; Cerar, A. Dextran sodium sulphate colitis mouse model: Traps and tricks. J. Biomed. Biotechnol. 2012, 2012, 718617. [CrossRef] [PubMed]

32. Riccadis, F.; Minale, L.; Iorizzi, M.; Debitus, C.; Lévi, C. Marine sterols. Side-chain-oxygenated sterols, possibly of abiotic origin, from the new Caledonian sponge Stellodoryx chlorophylla. J. Nat. Prod. 1993, 56, 282-287. [CrossRef]

33. Sakamoto, B.; Hokama, Y.; Horgen, F.D.; Scheuer, P.J.; Kan, Y.; Nagai, H. Isolation of a sulfoquinovosyl monoglycerol from Bryopsis sp. (Chlorophyta): Identification of a factor causing a possible species-specific ecdysis response in Gambierdiscus toxicus (Dinophyceae). J. Phycol. 2000, 36, 924-931. [CrossRef]

34. Hanashima, S.; Mizushina, Y.; Yamazaki, T.; Ohta, K.; Takahashi, S.; Sahara, H.; Sakaguchi, K.; Sugawara, F. Synthesis of sulfoquinovosylacylglycerols, inhibitors of eukaryotic DNA polymerase $\alpha$ and $\beta$. Bioorg. Med. Chem. 2001, 9, 367-376. [CrossRef]

35. Sheu, J.; Wang, G.; Sung, P.; Duh, C. New cytotoxic oxygenated fucosterols from the brown alga Turbinaria conoides. J. Nat. Prod. 1999, 62, 224-227. [CrossRef]

36. Aratani, Y. Myeloperoxidase: Its role for host defense, inflammation, and neutrophil function. Arch. Biochem. Biophys. 2018, 640, 47-52. [CrossRef]

37. Singer, I.I.; Kawka, D.W.; Schloemann, S.; Tessner, T.; Riehl, T.; Stenson, W.F. Cyclooxygenase 2 is induced in colonic epithelial cells in inflammatory bowel disease. Gastroenterology 1998, 115, 297-306. [CrossRef]

38. Lin, X.; Sun, Q.; Zhou, L.; He, M.; Dong, X.; Lai, M.; Liu, M.; Su, Y.; Jia, C.; Han, Z.; et al. Colonic epithelial mTORC1 promotes ulcerative colitis through COX-2-mediated Th17 responses. Mucosal Immunol. 2018, 11, 1663-1673. [CrossRef]

39. Sands, B.E.; Kaplan, G.G. The role of TNFalpha in ulcerative colitis. J. Clin. Pharmacol. 2007, 47, 930-941. [CrossRef]

40. Galvez, J. Role of Th17 cells in the pathogenesis of human IBD. ISRN Inflamm. 2014, 2014, 928461. [CrossRef]

41. Fontenot, J.D.; Gavin, M.A.; Rudensky, A.Y. Foxp3 programs the development and function of CD4+CD25+ regulatory T cells. Nat. Immunol. 2003, 4, 330-336. [CrossRef] [PubMed]

42. Hori, S.; Nomura, T.; Sakaguchi, S. Control of regulatory T cell development by the transcription factor Foxp3. Science 2003, 299, 1057-1061. [CrossRef]

43. van Herk, E.H.; Velde, A.A.T. Treg subsets in inflammatory bowel disease and colorectal carcinoma: Characteristics, role, and therapeutic targets. J. Gastroenterol. Hepatol. 2016, 31, 1393-1404. [CrossRef] [PubMed]

44. Agbanoma, G.; Li, C.; Ennis, D.; Palfreeman, A.C.; Williams, L.M.; Brennan, F.M. Production of TNF- $\alpha$ in macrophages activated by $\mathrm{T}$ cells, compared with lipopolysaccharide, uses distinct IL-10-dependent regulatory mechanism. J. Immunol. 2012, 188, 1307-1317. [CrossRef] [PubMed]

45. Egwuagu, C.E. STAT3 in CD4+ T helper cell differentiation and inflammatory diseases. Cytokine 2009, 47, 149-156. [CrossRef]

46. Cooper, H.S.; Murthy, S.N.; Shah, R.S.; Sedergran, D.J. Clinicopathologic study of dextran sulfate sodium experimental murine colitis. Lab. Investig. 1993, 69, 238-249.

Publisher's Note: MDPI stays neutral with regard to jurisdictional claims in published maps and institutional affiliations.

(C) 2020 by the authors. Licensee MDPI, Basel, Switzerland. This article is an open access article distributed under the terms and conditions of the Creative Commons Attribution (CC BY) license (http://creativecommons.org/licenses/by/4.0/). 